\title{
DEVELOPMENT OF A DATA-DRIVEN MODEL TO PREDICT LANDSLIDE SENSITIVE AREAS
}

\author{
Seyed Ahmad ESLAMINEZHAD ${ }^{1}$ (D), Davoud OMARZADEH ${ }^{\text {(D) }}$, Mobin EFTEKHARI ${ }^{*}$ (i), \\ Mohammad AKBARI
}

DOI: 10.21163/GT_2021.161.09

\begin{abstract}
:
The occurrence of landslides has always been a problem in spatial planning as one of the environmental threats. The aim of the present study is to estimate the landslide sensitive areas in the Urmia Lake basin based on determining effective criteria and spatial and non-spatial data-driven models. The criteria used in this research include distance to faults, distance to roads, distance to hydrology network, land use, lithology, soil classes, Elevation, slope, aspect and Precipitation. The novelty of this study is to present new combination approaches to determine the effective criteria in landslide sensitive areas (Urmia Lake basin). In this regard, the geographically weighted regression (GWR) with exponential and bi-square kernels and artificial neural network (ANN) combined with a binary particle swarm optimization algorithm (BPSO). The best value of the fitness function (1-R2) for ANN, GWR with the exponential kernel, and GWR with bi-square kernel was obtained 0.2780, 0.07453, and 0.0022, respectively, Which indicates higher compatibility of the bi-square kernel than the other models. It was also found that the criteria used have a significant effect on the landslide sensitive zoning.
\end{abstract}

Key-words: Landslide, geographically weighted regression, artificial neural network, binary particle swarm optimization algorithm.

\section{INTRODUCTION}

Natural disasters, as man's greatest natural enemy, kill and injure hundreds of people annually and leave millions homeless around the world. Landslides are one of the most devastating natural disasters in sloping areas (Oktorie, 2017). Landslides and soil mass movements are a form of geomorphological processes and are considered as a special type of natural disasters from the perspective of natural hazard management. The occurrence of this type of phenomenon every year in some parts of our country as well as other parts of the world causes significant human, financial and environmental losses (Zhang et al., 2020). Identifying landslide-prone areas by zoning hazard capability with appropriate statistical models is one of the first steps in reducing potential damage and landslide risk management (Ciurleo et al., 2017). Damages caused by natural hazards have always destroyed many human-made structures and facilities, and the identification of high-risk areas should be considered as one of the main programs in land management studies (Jin et al., 2019) .

Environmental issues and forecasting the risks and damages caused by it using spatial modeling is one of the main branches of GIS today, which provides accurate and up-to-date results with very high accuracy compared to reality. In most sources, landslides are considered synonymous with mass movements (Lo et al., 2018). According to this definition and classification of hazards, by collecting data related to these movements, areas with a high probability of occurrence can be identified and the establishment of sensitive facilities and the development of the body of the city in those areas can be

${ }^{1}$ Department of surveying and Geomatics Engineering, College of Engineering, University of Tehran, Tehran, Iran.Ahmad.eslami73@ut.ac.ir.

${ }^{2}$ Geography Information System and Remote Sensing, University of Tabriz, Iran. davoud.omarzadeh@stud.sbg.ac.at.

3* Young Researchers and Elite Club, Mashhad Branch, Islamic Azad University, Mashhad, Iran. mobineftekhari@yahoo.com.

${ }^{4}$ Department of Civil Engineering, University of Birjand, Birjand, Iran. moakbari@birjand.ac.ir. 
prevented. Dozens of landslides occur in different parts of the country every year and threaten many residential areas, roads, and facilities (Amir Yazdadi and Ghanavati, 2016). There are many methods for zoning landslide sensitive areas, but in general, these methods are divided into two categories: data-driven and knowledge-driven models. Data-driven models are highly effective in known areas or areas where the number of known evidence is statistically sufficient (references data). In these models, the purpose is to identify new locations for more detailed work, while in knowledge-driven models, they are effective in less known environments or where there are few targets in the area. Weight estimates and class estimates are based on expert judgment and do not require evidence of an answer (Guevara et al. 2018; Wang and Liu 2019). Numerous studies have been conducted on Landslide zoning maps with approaches based on data-driven and knowledge-driven models, to name a few:

Neaupane and Piantanakulchai (2006) presented an ANP model for assessing landslide risk in a fragile mountainous terrain in the eastern part of Nepal. The results showed that the ANP model can achieve a complex relationship between landslide control factors and minimize the error caused by subjective judgment. Bai et al. (2010) used logistic regression for landslide susceptibility map in the Zhongxian-Shizhu region (China). The results showed that $2.8 \%$ of the study area was identified as very sensitive, while very low, low, medium and high areas covered $18.2 \%, 36.2 \%, 26.7 \%$ and $16.1 \%$, respectively. From the region, the quality of the sensitivity map was confirmed, respectively, and the percentage of correct classification and mean square error values (RMSE) for the validation data were $81.4 \%$ and 0.392, respectively. Felicísimo et al. (2013) used four methods of multiple logistic regression (MLR), multivariate adaptive regression splines (MARS), classification and regression trees (CART), and maximum entropy (MAXENT) to landslide susceptibility (Deba Valley, Northern Spain). The results of this study show that the best AUC values were obtained for single models MLR (0.76), MARS (0.76), CART (0.77) and MAXENT (0.78). Xu et al. (2015) conducted a study on landslide sensitivity analysis using a combination of computer science and GIS and artificial neural network methods in the three valleys region. In the mentioned research, geological layers, distance to fault, slope, aspect, precipitation, distance to river, land user, distance to road, water difference index, and normalized differential index of vegetation have been used. According to the results, the accuracy of the model is $88 \%$ and the result of comparing the actual recorded data with the product of this research indicates the high accuracy of the model. Rajabi et al. (2016) investigated the possibility of landslides in the Azarshahr Chay catchment using fuzzy logic. In this research, the criteria of distance to road, distance to fault, distance to river, land use, lithology, elevation classes, slope, and aspect have been used. The results of this study show that 24.47, 26.4, 25.92, 17.59, and 5.77\% of the area are in very low, low, medium, high, and very high probability occurrence classes, respectively. Ghorbanzadeh et al. (2019) have conducted a study on the application of multi-criteria spatial decision making and location of potential tourism areas in East Azerbaijan province in which the combination of Analytical Network Process (ANP) and Ordered Weighted Averaging (OWA) have been used to achieve potential nature areas. Baharvand et al. (2020) used fuzzy logic and GIS methods for landslide susceptibility zoning in the Sorkhab basin as a part of the Zagros. The results showed that a 0.9 fuzzy gamma operator has high accuracy for the LSZ map in the study area. Also, the accuracy of the landslide susceptibility zoning map showed that there was a strong $\left(\mathrm{R}^{2}\right)$ relationship between the sensitivity classes.

Landslide zoning map production is a topic that has received a lot of attention so far, but among the studies conducted, some points have received less attention; first, none of these studies provide an adequate combination of criteria for landslide zoning. Second, proper analysis has not been used to determine the optimal combination of effective criteria and to prepare a landslide zoning map based on the effective criteria. In this study to recognizing the vulnerability of Urmia Lake basin to landslide sensitive, due to the availability of landslide reference map in the region, the combination of spatial and non-spatial data-driven models including artificial neural network (ANN) and geographically weighted regression (GWR) with binary particle swarm optimization (BPSO) were used to prepare Landslide zoning map based on determining the optimal combination of effective criteria. 


\section{STUDY AREA}

The study area in the present study includes the catchment area of Lake Urmia, parts of East Azerbaijan province, and parts of West Azerbaijan province, as well as part of Kurdistan province. This catchment is one of the closed catchments in Iran, which is located in the northwest of the country. The highest heights of this basin include Sabalan with a height of 4811 meters and Sahand with a height of 3707 meters and the lowest point of the basin is Lake Urmia with an average height of 1280 meters. According to the Meteorological Organization, the average rainfall in the basin is 550 $\mathrm{mm}$ and its main source is Mediterranean currents. The most important rivers of this basin are Ajichai, Zarrinehrood, and Siminehrood. The geographical position of the study basin includes 44 degrees and 21 minutes east to 47 degrees and 91 minutes east and 35 degrees and 35 minutes north to 38 degrees and 49 minutes north (Fig. 1).

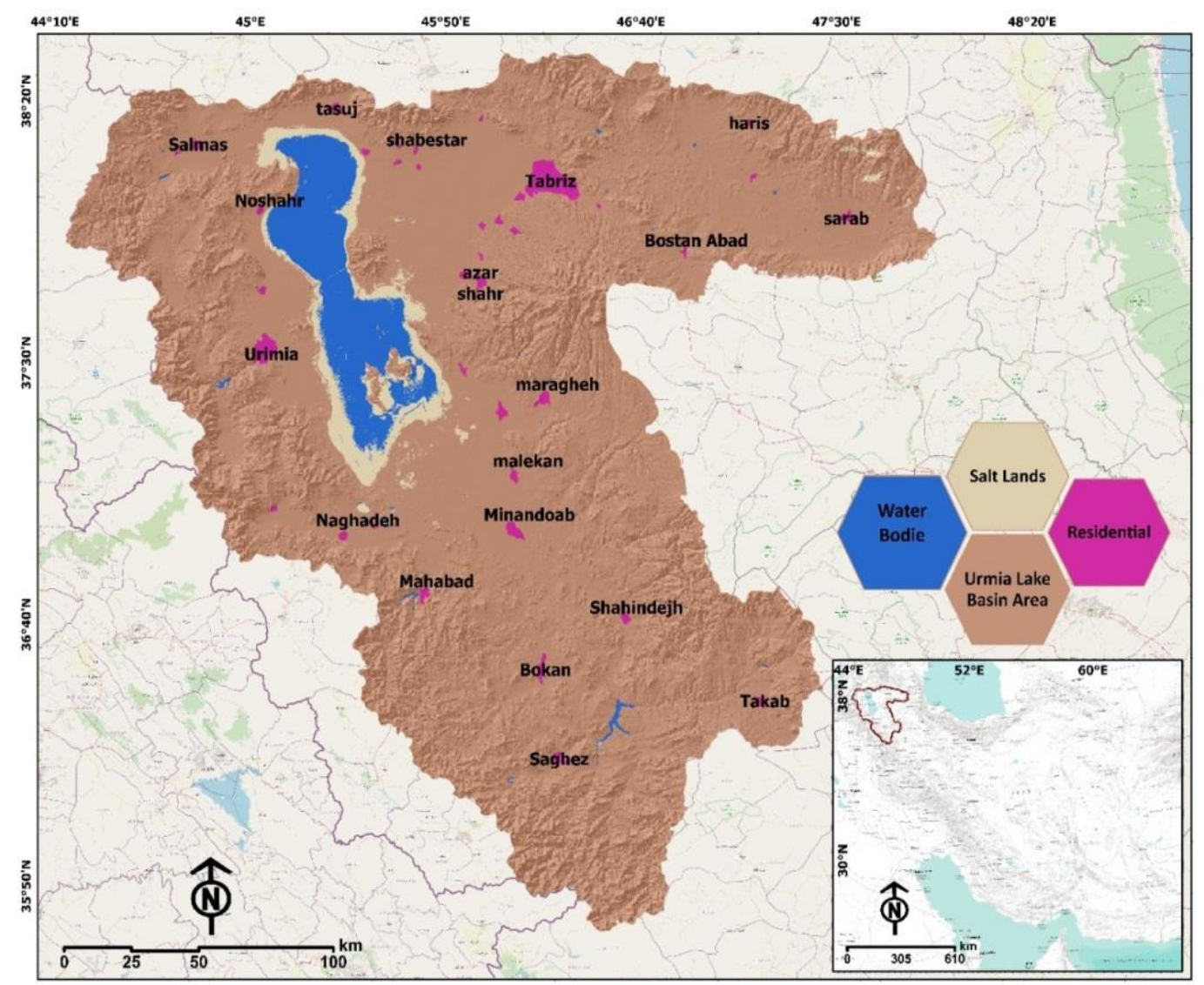

Fig. 1. Geographical location of Lake Urmia catchment in Iran.

\section{DATA AND METHODS}

\subsection{Spatial criteria affecting landslide}

According to Table 1, in this study, the spatial criteria affecting landslide are considered as independent variables. These criteria, in the order mentioned, form the particle dimension of the BPSO algorithm. Also, the flowchart of the research is also shown in Fig. 2. 
Independent variables in this study.

Table 1.

\begin{tabular}{|c|c|c|c|}
\hline Order & Criteria & Order & Criteria \\
\hline 1 & Distance to faults & 6 & Soil classes \\
\hline 2 & Distance to roads & 7 & Elevation \\
\hline 3 & Distance to hydrology network & 8 & Slope \\
\hline 4 & Land use & 9 & Aspect \\
\hline 5 & Lithology & 10 & Precipitation \\
\hline
\end{tabular}

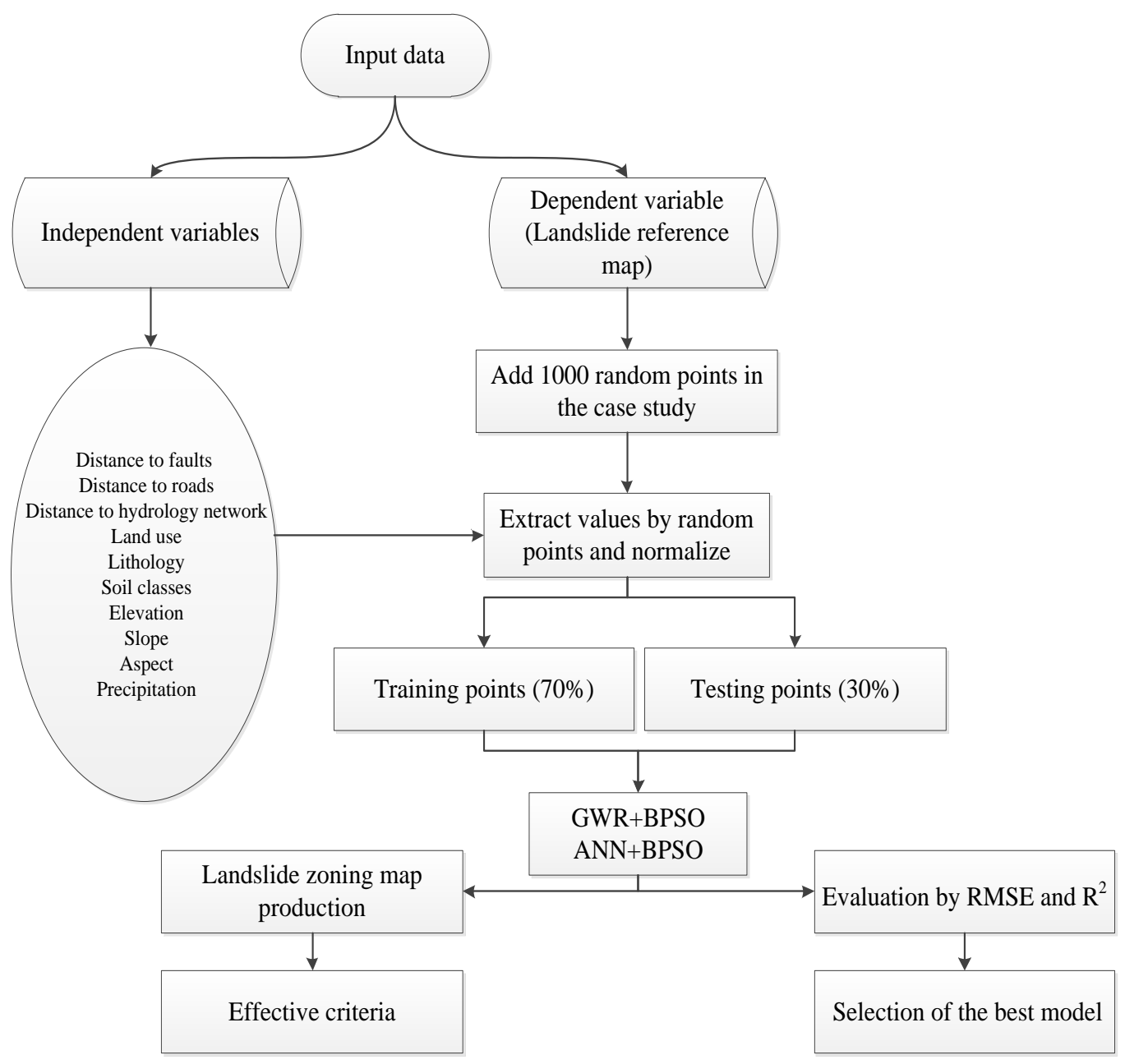

Fig. 2. Flowchart of steps taken in the research.

The spatial criteria affecting landslide was obtained from the Geological Survey and Mineral Exploration of Iran. For implementation, each of the criteria was produced in the form of a raster map with a pixel size of 30 meters. According to Fig. 3, the maps of these criteria are shown in a normalized way. 
(a)

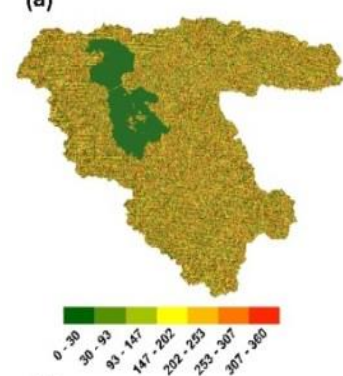

(e)

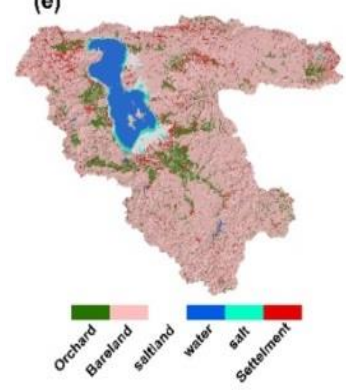

(b)

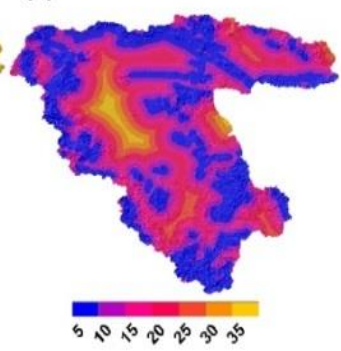

(f)

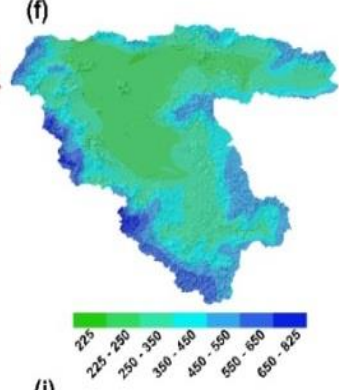

(i)

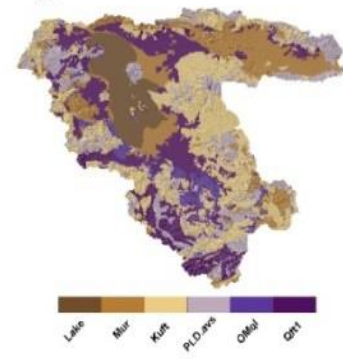

(c)

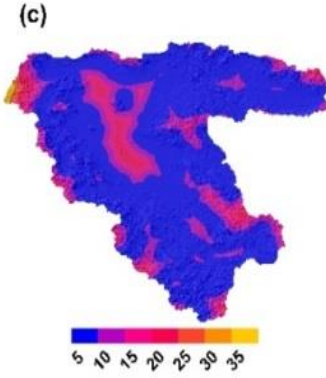

(g)

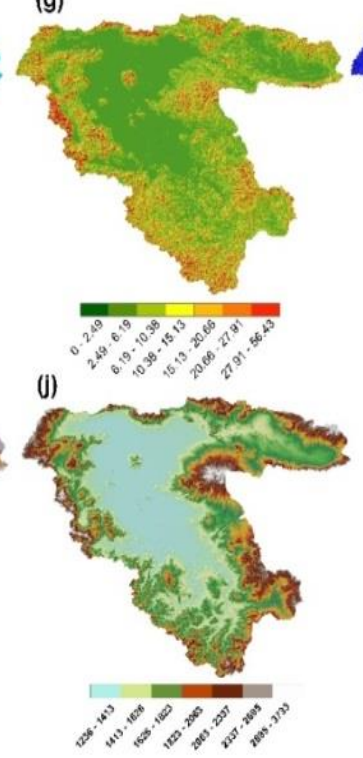

(d)

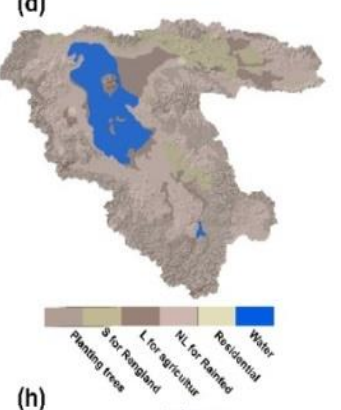

(h)

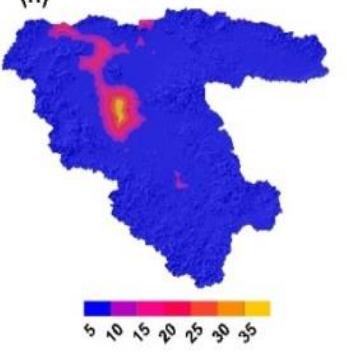

Fig. 3. Map of criteria used in landslide zoning (a) Aspect (b) Distance to fault (c) Distance to road (d) Soil type (e) Land use (f) Precipitation (g) Slope (h) Distance to hydrology network (i) Lithology (j) Elevation.

\subsection{Proposed methods}

\subsubsection{Artificial neural network}

Artificial neural networks are one of the computational methods inspired by the neural system of the human brain. One of the remarkable characteristics of this type of network is their ability to learn and the ability to generalize this learning, because of this feature, they make it possible to learn to understand patterns (El_Jerjawi and Abu-Naser, 2018). The most important advantage of artificial neural networks over regression methods for modeling a pattern is that there is no need for an initial model in linking input and output data (Lee et al., 2018). Based on the intrinsic relationships between data, a linear or nonlinear model is established between independent and dependent variables.

In this study, a multilayer perceptron neural network has been used to model landslide sensitive. This type of neural network consists of a set of neurons arranged in different layers in a row. The law of multilayer perceptron learning is called the error propagation rule, which is used to estimate unknown network parameters. The multilayer perceptron works in such a way that a pattern is supplied to the network and its output is calculated. Actual output values and desired output cause the network coefficients to change; in such a way that a more accurate output is obtained in later stages. To succeed in network training, its output must be gradually brought closer to the desired output and the error rate must be reduced. The design ANN used in this study is illustrated in Fig. 4. 


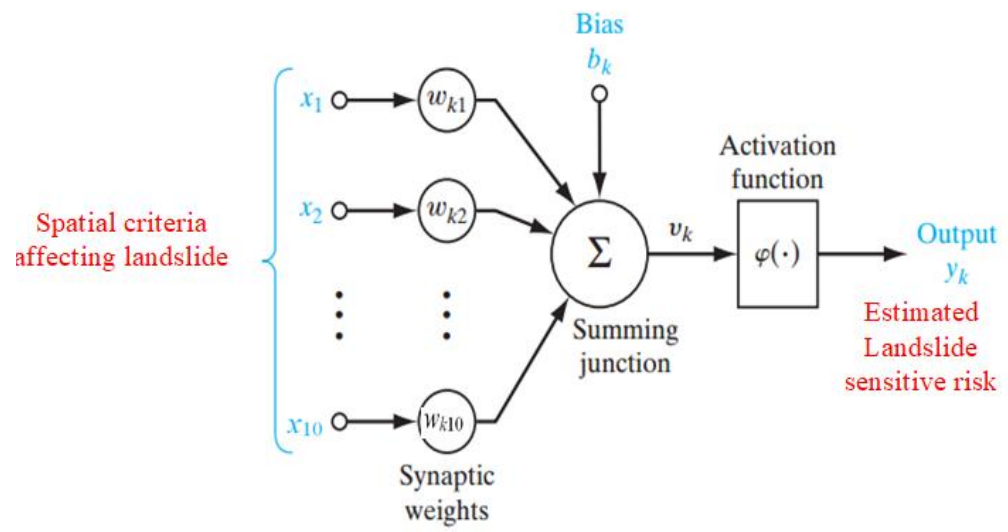

Fig. 4. ANN architecture applied in this study (Lee et al., 2018).

\subsubsection{Geographically weighted regression}

According to spatial autocorrelation and spatial non-stationarity properties for spatial data, it is less possible to use basic global regressions such as Ordinary Least square (Murray et al., 2020). In this model, the spatial dependencies between the events are considered as weight matrices, and due to the heterogeneity of the environmental factors and the existence of local variation, regression coefficients of the GWR model for observation are measured locally (Wu, 2020). The equation of the GWR model is calculated as Eq. 1 (Fotheringham and Oshan, 2016):

$$
y_{i}=\sum_{j=0}^{n} \beta_{j}\left(u_{i}, v_{i}\right) x_{j}+\varepsilon_{i}
$$

where:

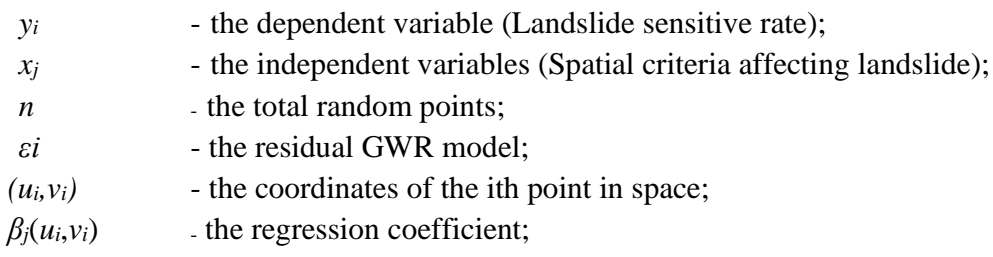

To calculate the spatial weight matrix, it is necessary to specify the desired kernel function. According to previous research, this study used two kernels including exponential and bi-square these two kernels which are calculated as Eq. 2 and Eq. 3, respectively (Oshan et al., 2019; Fotheringham and Oshan, 2016):

$$
\begin{gathered}
W\left(u_{i}, v_{i}\right)=\exp \left(-\left(\frac{\left|d_{i j}\right|}{b}\right)\right) \\
W\left(u_{i}, v_{i}\right)=\left\{\begin{array}{c}
\left(1-\left(\frac{d_{i j}}{b}\right)^{2}\right)^{2} \quad\left|d_{i j}\right|<b \\
0 \text { otherwise }
\end{array}\right.
\end{gathered}
$$

where:

$d_{i j} \quad-$ the euclidean distance value between two observations i and $\mathrm{j}$;

$b \quad$ - the bandwidth value;

The regression coefficients are different for each location, so in the GWR model, local variation of the regression coefficients can be obtained by the standard deviation function according to Eq. 4 (Wu, 2020): 


$$
S E=\sqrt{\sum_{i=1}^{n} \frac{\left(\beta_{i j}-\beta_{j}\right)^{2}}{n}}
$$

where:

$\beta_{i j} \quad-$ the regression coefficient for the factor $\mathrm{j}$ in the observation $\mathrm{i}$;

$\beta_{j} \quad-$ the mean regression coefficient of factor $j$;

$n \quad-$ the total random points;

To evaluate the ANN and GWR models output the Coefficient of Determination $\left(R^{2}\right)$ is usually used to measur'e the goodness of fit and the RMSE value measure the residuals distribution of the observation, which are obtained based on Eq. 5 and Eq. 6 (Fotheringham and Oshan, 2016):

$$
\begin{gathered}
R^{2}=1-\frac{\sum_{i=1}^{n}\left(y_{i}-\hat{y}_{i}\right)^{2}}{\sum_{i=1}^{n}\left(y_{i}-\bar{y}\right)^{2}} \\
R M S E=\sqrt{\frac{\sum_{i=1}^{n}\left(y_{i}-\hat{y}_{i}\right)^{2}}{n}}
\end{gathered}
$$

where:

$\begin{array}{ll}y_{i} & \text { - the value for observation; } \\ y_{i} & \text { - the estimated value for observation } i ; \\ n & \text { - the total random points; } \\ \bar{y}_{i} & \text { - the mean value for total observations; }\end{array}$

\subsubsection{Binary particle swarm optimization}

The PSO algorithm is an optimization algorithm that makes it less likely to be captured at a local minimum and can search uncertain and complex areas based on probabilistic rules (Aghbashlo et al., 2019). Also in this algorithm, the solution of the proposed path is not dependent on the initial population and starting from each point in the search space, the solution converges to the optimal solution (Abed and Ahmad, 2020). After a while, Kennedy and Eberhart (1997) introduced the Binary PSO algorithm, which, unlike the continuous version of it, is limited to having zero and one (binary) variables and the velocity value can change a particle from zero to one. According to the purpose of this study, The BPSO algorithm has been used. In this algorithm, Eq. 7 and Eq. 8 are used to update the velocity and position of each particle (Kennedy and Eberhart, 1997):

$$
\begin{gathered}
V_{i}(t+1)=w \times V_{i}(t)+c_{1} \times r_{1} \times\left(\text { pbest }-X_{i}(t)\right)+c_{2} \times r_{2} \times\left(\text { gbest }-X_{i}(t)\right) \\
X_{i}(t+1)=\left\{\begin{array}{cc}
1 & \rho \leq \operatorname{sig}\left(v_{i}^{t+1}\right) \\
0 & \text { Otherwise }
\end{array}\right.
\end{gathered}
$$

where:

$\begin{array}{ll}V_{i}(t) & \text { - the velocity of the particle } i ; \\ X_{i}(t) & \text { - the position of the particle } i ; \\ V_{i}(t+1) & \text { - velocity of the particle } i \text { in the next position; } \\ X_{i}(t+1) & \text { - the position of the particle } i \text { in the next position; } \\ \text { pbest } & \text { - the best position of the experience for the particle } i ; \\ \text { gbest } & \text { - the best position experienced in all particles; } \\ \mathrm{c}_{1} & \text { - the personal learning coefficient; } \\ c_{2} & \text { - the collective learning coefficient; } \\ w & \text { - the inertia weight; } \\ r_{1}, \text { rand } \rho & \text { - the random numbers in the range [0.1]; }\end{array}$


In this study the steps of the BPSO algorithm (In combination with the ANN and GWR models) are as follows which showed in Fig. 5:

1. Give the initial value to a population of particles with random positions and velocities.

2. Training ANN and GWR models and calculating the fitness function $\left(\mathrm{R}^{2}\right)$ of each particle in this population.

3. Stop the BPSO algorithm (reach 100 iterations), otherwise go to step 4. If the algorithm reaches the condition of stopping, then the selected criteria are the same effective parameters in estimating landslide risk.

4. Determine the pbest and gbest for particles.

5. Calculate the velocity of each particle and move to the next position based on the relations (Go to step 2).

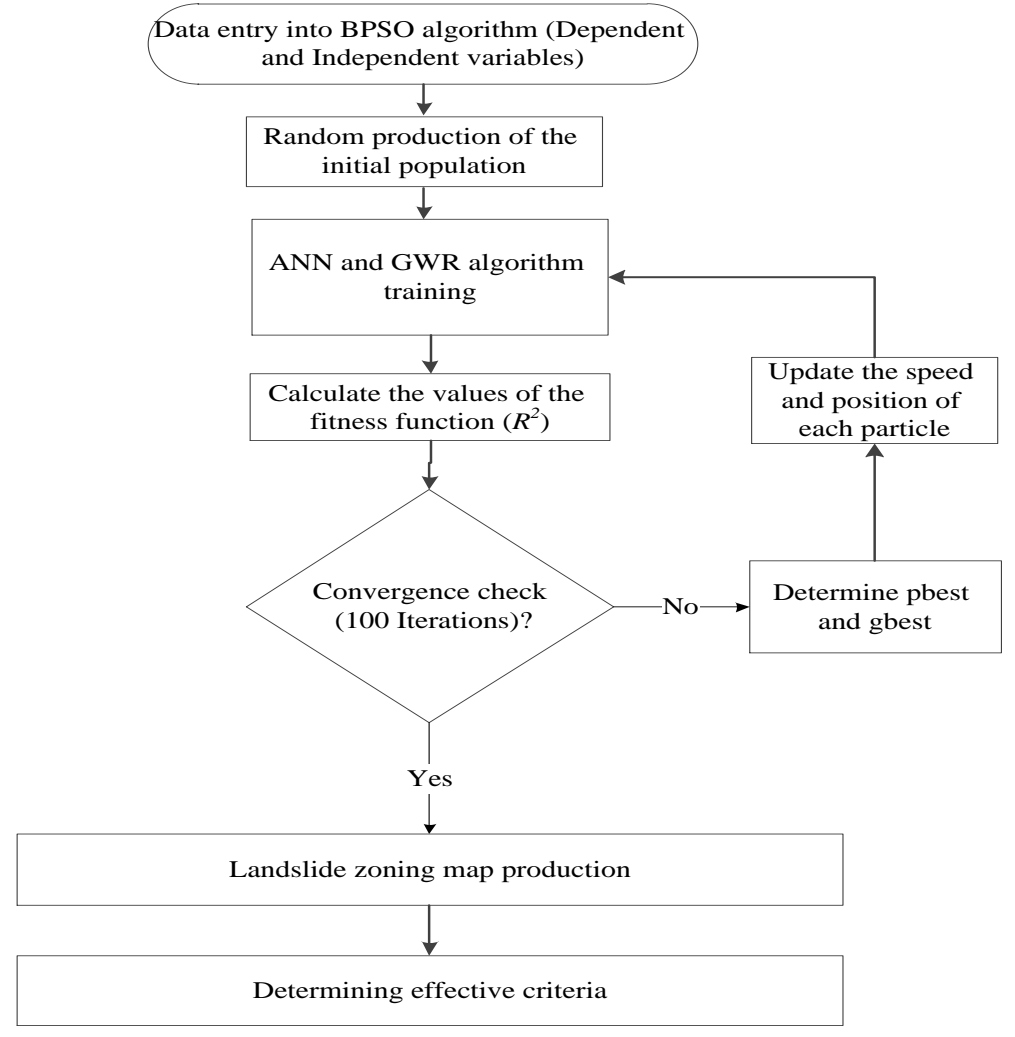

Fig. 5. Calculation steps of the recommended models.

\section{RESULTS AND DISCUSSIONS}

\subsection{Data preparation}

In order to implement the proposed models, it is necessary to produce random points in the desired area. The Landslide is the result of the reference map related to June 2017 (Fig. 6a), which has been obtained from Geological Survey \& Mineral Explorations of Iran. Then, according to Fig. 6b, 1000 points were generated randomly and uniformly in the study area (Elfil and Negida, 2019). Then the values of all available information criteria for these points were calculated (In a normalized way). Of these, $70 \%$ for training and $30 \%$ for testing were randomly selected and used equally for all models. Based on previous research and trial and error method, a ratio of 70:30 was selected (Paulino et al., 2019). In article this ratio gives the best performance results. 


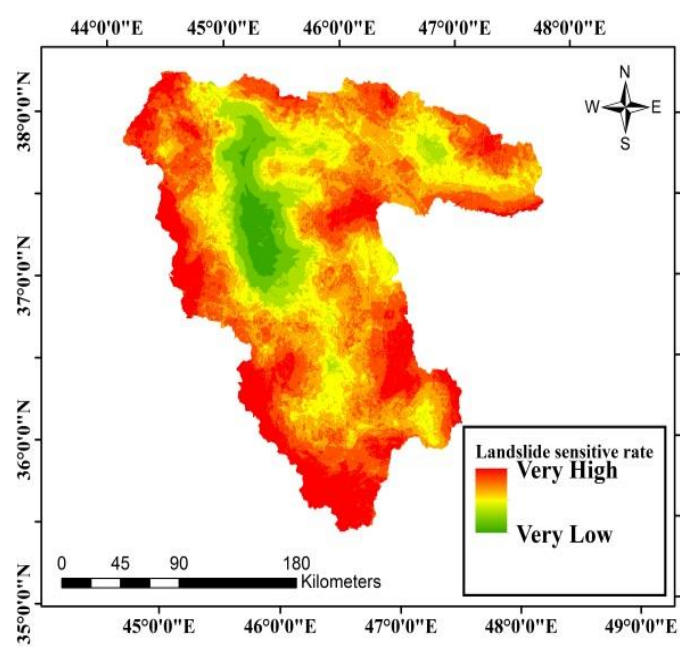

(a)

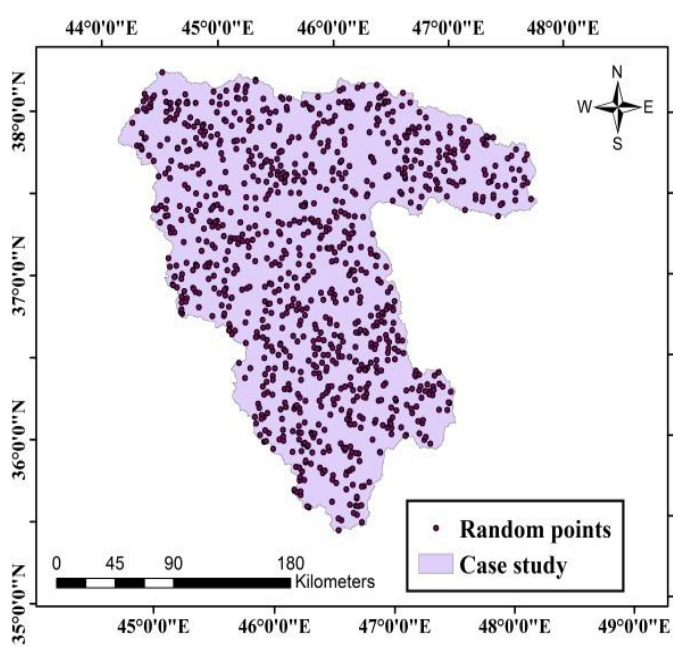

(b)

Fig. 6. (a) The landslide reference map (b) The random point created in the case study.

The correlation between the criteria from Eq. 9 was examined (Aad et al., 2014):

$$
r=\frac{\sum_{i=1}^{n}\left(x_{i}-\bar{x}\right)\left(y_{i}-\bar{y}\right)}{n \cdot \sigma_{x} \cdot \sigma_{y}}
$$

where:

$\bar{x}$ and $\bar{y} \quad-$ the mean of data $\mathrm{x}$ and $\mathrm{y}$;

$n \quad-$ the total data;

$\sigma_{x}$ and $\sigma_{\mathrm{y}} \quad$ - the deviation of data $\mathrm{x}$ and $\mathrm{y}$;

As shown in Fig. 7, the correlation between the criteria is near 0 . Therefore, all criteria entered the algorithms.

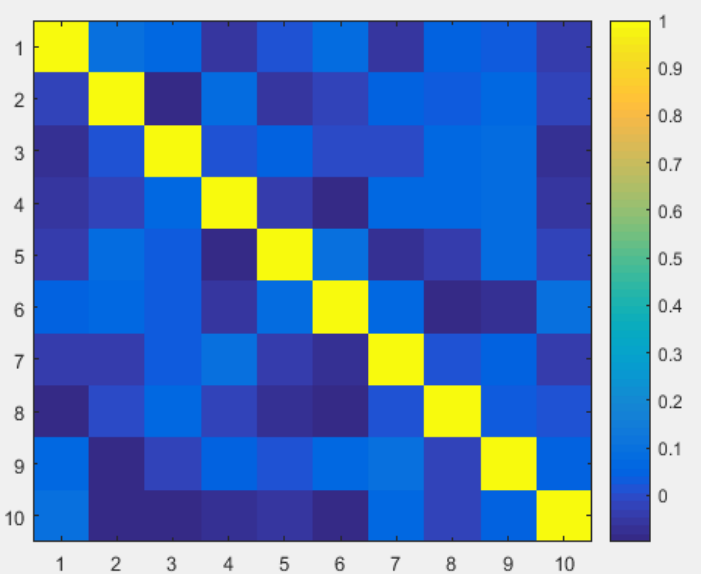

\begin{tabular}{cc} 
Order & Criteria \\
\hline 1 & Distance to faults \\
2 & Distance to roads \\
3 & Distance to hydrology network \\
4 & Land use \\
5 & Lithology \\
6 & Soil classes \\
7 & Elevation \\
8 & Slope \\
9 & Aspect \\
10 & Precipitation
\end{tabular}

Fig. 7. Correlation matrix between criteria

\subsection{Implement data-driven models}

For the implementation of the ANN and GWR models, $70 \%$ of the total data was used for training and $30 \%$ of the total data was used for testing, and all data were normalized before entering the algorithms (Paulino et al., 2019). Due to the fact that one of the most important parameters for evaluating data-driven models (Model compatibility with data) is the Coefficient of Determination 
parameter $\left(R^{2}\right)$, therefore, the BPSO algorithm fitness function has been selected to minimize the value of $1-R^{2}$ (Fotheringham and Oshan, 2016). The optimal values of the initial parameters of the BPSO algorithm were selected based on the experiments obtained from different iterations and through trial and error according to Table 2. The condition for stopping to simplify the implementation process is the number of specific executions.

Table 2.

Set Parameters in the BPSO algorithm.

\begin{tabular}{|c|c|c|c|}
\hline Parameters & Value & Parameters & Value \\
\hline Swarm size & 30 & $C_{2}$ & 2 \\
\hline Total iterations & 100 & $W$ & 1 \\
\hline$C_{I}$ & 2 & Minimum and maximum velocity & {$[-4,4]$} \\
\hline
\end{tabular}

Fig. 8 shows the swarm structure of the BPSO algorithm in this study, which the criteria mentioned in Table 1 form the particle dimension of the BPSO algorithm.

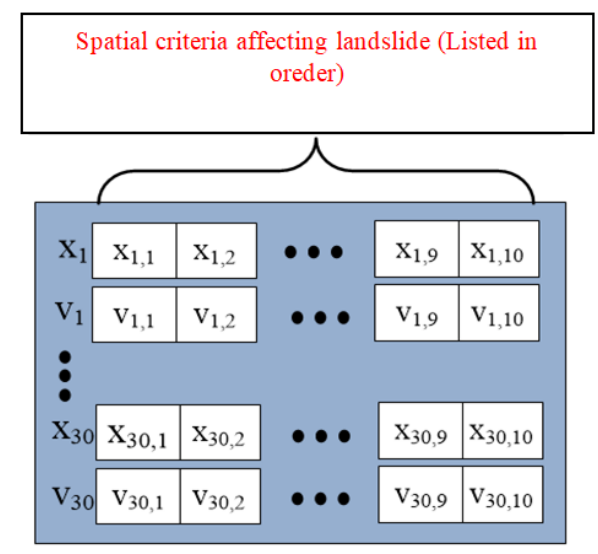

Fig. 8. Swarm structure of the BPSO algorithm.

Due to the random nature of the BPSO algorithm and based on previous research, this algorithm with the desired number of iterations was repeated 10 executions and the Best of these 10 executions was considered as the final output (Saeidian et al., 2018). According to Fig. 9a, by performing the combination of the ANN model and the BPSO algorithm, the best value of fitness function $\left(1-\mathrm{R}^{2}\right)$ was obtained 0.2780 (the best of 10 executions). Also, According to Fig. $9 \mathbf{b}$ for the ANN model, four criteria of distance to faults, distance to roads, distance to hydrology network and aspect were determined as effective criteria in predicting landslide risk. In fact, Fig. $\mathbf{9 b}$ shows the best particle in terms of fitness function $\left(\mathrm{R}^{2}\right)$ among all particles (30 particles) in the 100th iteration of the BPSO algorithm.

Then, the GWR model with two exponential and bi-square kernels and BPSO algorithm was combined to determine the effective criteria in predicting landslide risk. To implement the GWR model, the random points' coordinates were used as inputs in the weight matrix. According to Fig. 10, the best value of fitness function $\left(1-\mathrm{R}^{2}\right)$ for combination the GWR model with two exponential and bi-square kernels and the BPSO algorithm, was obtained 0.07453 and 0.0022 (the best of 10 executions), respectively. Also, According to Fig. 11 for the GWR model with the exponential kernel, nine criteria of Distance to roads, Distance to hydrology network, Land use, Lithology, Soil classes, Elevation, Slope, Aspect, and Precipitation and for the bi-square kernel, eight criteria of Distance to roads, Land use, Lithology, Soil classes, Elevation, Slope, Aspect, and Precipitation were determined as effective criteria in predicting landslide risk. 


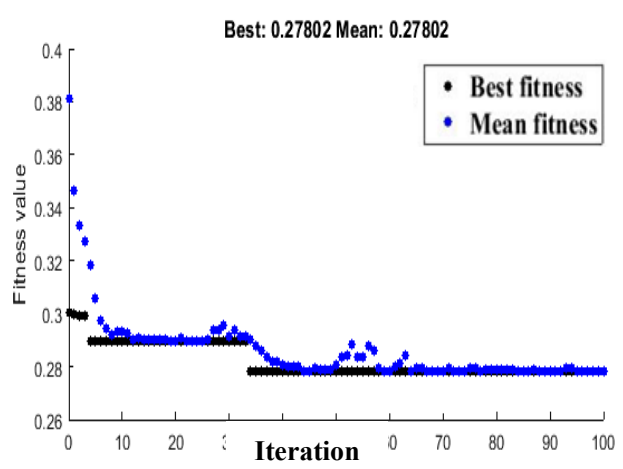

(a)

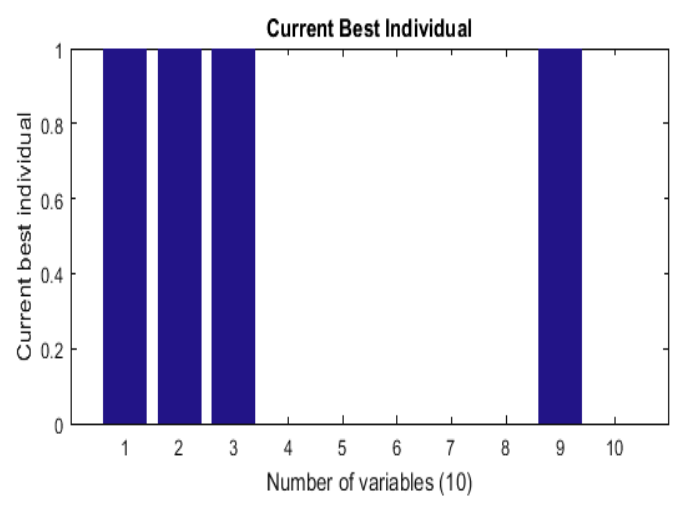

(b)

Fig. 9. (a) The best value of fitness function by combining of ANN model and BPSO algorithm (b) Effective criteria in predicting landslide risk by combining of ANN model and BPSO algorithm
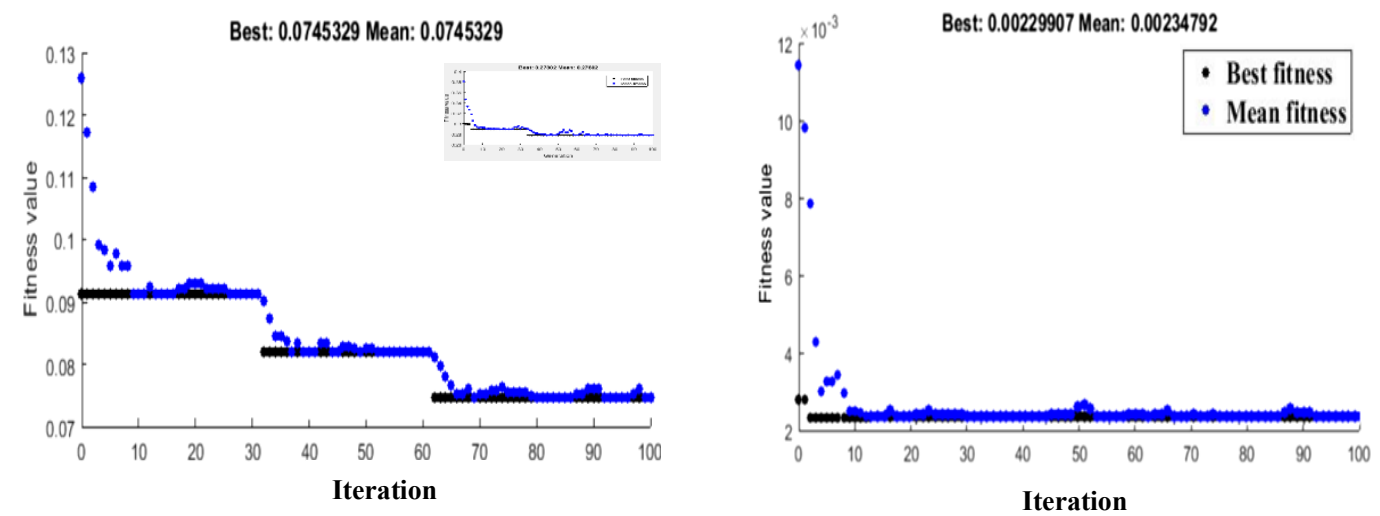

Fig. 10. The best value of fitness function by combining of GWR model and BPSO algorithm (a) Exponential kernel (b) Bi-square kernel

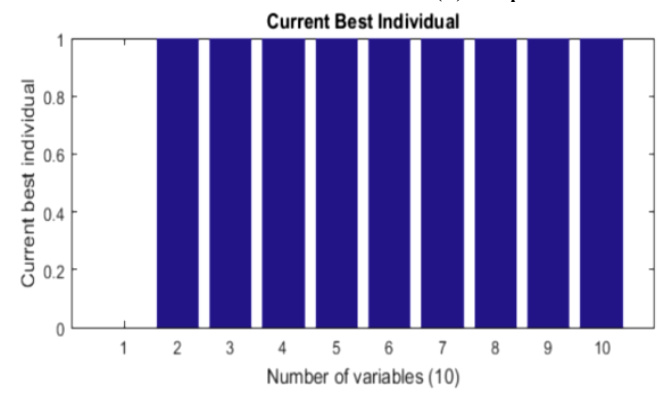

(a)

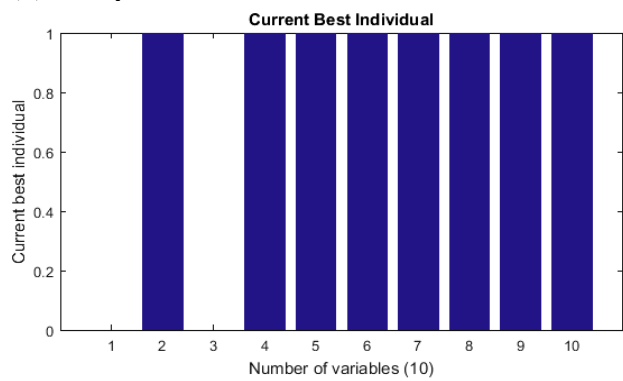

(b)

Fig. 11. Effective criteria in predicting landslide risk by combining of GWR model and BPSO algorithm (a) Exponential kernel (b) Bi-square kernel

In Fig. 12, the values of $\mathrm{R}^{2}$ and RMSE for the ANN and GWR models are shown. Accordingly, the bi-square kernel has higher accuracy in predicting landslide risk based on effective criteria. 


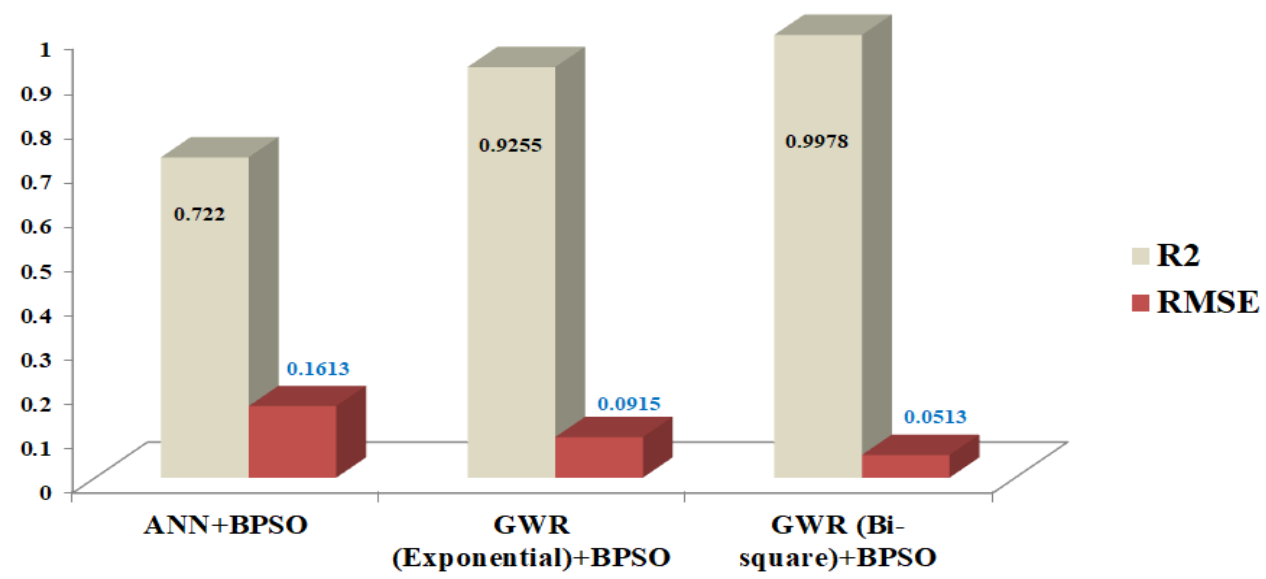

Fig. 12. Comparison of $A N N$ and GWR models in terms of $R^{2}$ and RMSE

According to Fig. 13, the maps of predicted landslide risk (based on effective criteria) by combining ANN and GWR models and BPSO algorithm showed in the range [0,1]. The estimated landslide risk is classified into five output classes according to the Equal Interval classification method. According to the results obtained from $\mathrm{R}^{2}$ value (goodness of fit) and the RMSE value (Residuals distribution of the observation and accuracy of model), the combination of GWR model with Bi-square kernel and BPSO algorithm has a higher ability to predict landslide risk, which showed in Fig. 13c.

As mentioned, since the regression coefficients are different for each location in the GWR model, local variation and spatial non-stationarity of the regression coefficients can be obtained by the standard deviation function. Fig. 14 shows the standard deviation of regression coefficients GWR model (with two exponential and bi-square kernels) for calculating the rate of local variation and spatial non-stationarity.

According to Fig. 14, for the GWR model with the exponential kernel, the relationship between soil classes and landslide risk with displacement has the most variation and the relationship between Precipitation and landslide risk has the least variation. Also, in the GWR model with the bi-square kernel, the relationship between aspect and landslide risk with displacement has the most variation and the relationship between Precipitation and landslide risk has the least variation. Finally, global Moran's index was used to determine the spatial autocorrelation of GWR model residuals, which is calculated from Eq. 10 (Zemestani and Soori, 2019):

$$
I=\frac{n \sum_{i=1}^{n} \sum_{j=1}^{n} W_{i j}\left(x_{i}-\bar{X}\right)\left(x_{j}-\bar{X}\right)}{S_{0} \sum_{i=1}^{n}\left(x_{i}-\bar{X}\right)^{2}}
$$

where:

$$
\begin{array}{ll}
x_{i} \text { and } x_{j} & \text { - estimated lanslide risk for random points } \mathrm{i} \text { and } \mathrm{j} ; \\
W_{i j} & \text { - the spatial weight matrix between random points } i \text { and } j ; \\
S_{0} & \text { - the total of all weights; } \\
\bar{X} & \text { - the mean estimated landslide risk for random points; } \\
n & \text { - the total random points; }
\end{array}
$$




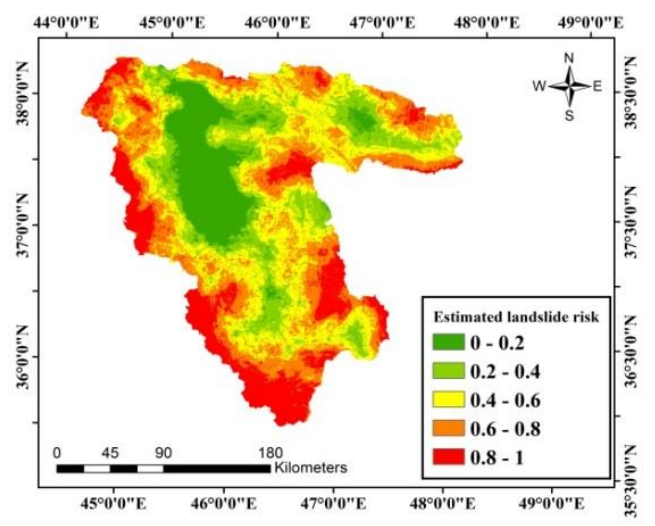

(a)

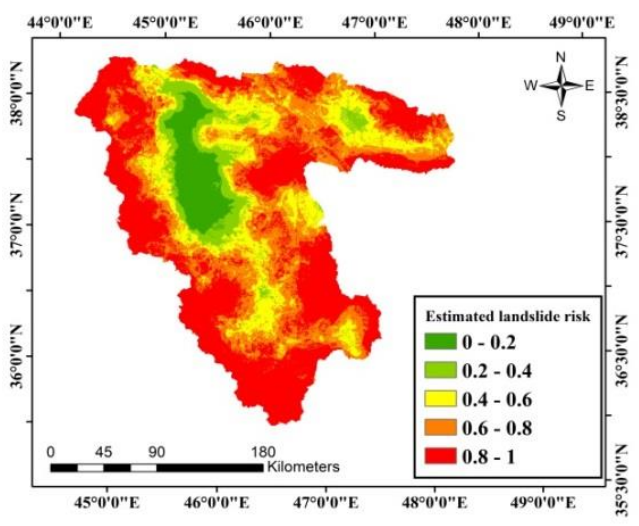

(b)

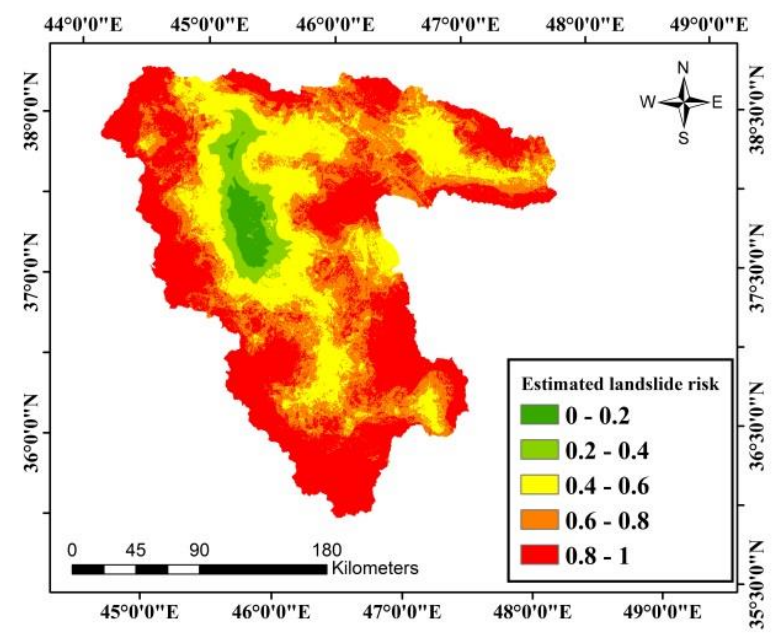

(c)

Fig. 13. The map of estimated landslide risk (a) ANN + BPSO (b) GWR (Exponential) + BPSO (c) GWR (Bi-square) + BPSO

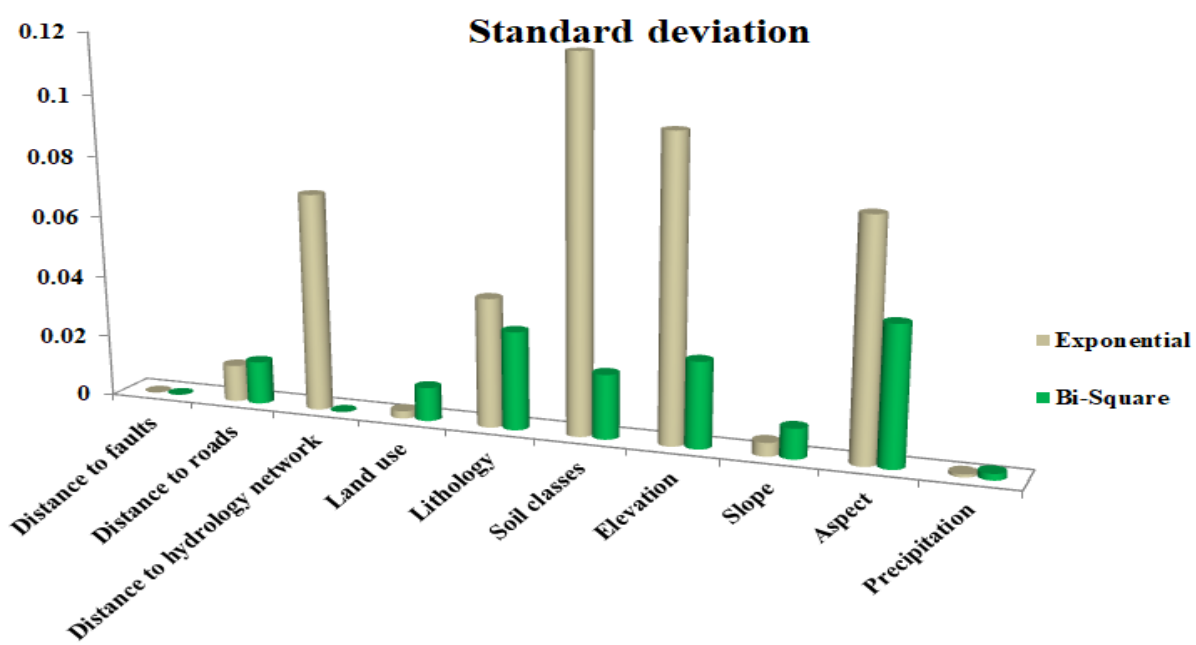

Fig. 14. The standard deviation of regression coefficients GWR model with exponential and bisquare kernels. 
Table 3, shows the values of global Moran's index for GWR model residuals with two exponential and bi-square kernels. According to Table 3 for the GWR model with the bi-square kernel, the Moran's index has a closer value to the expected index than the exponential kernel, which indicates the high ability of the bi-square kernel in modeling the spatial correlation of observations.

Table 2.

The values of Moran's index for GWR model residuals with two exponential and bi-square kernels.

\begin{tabular}{|c|c|c|}
\hline \multirow{2}{*}{ Parameters } & \multicolumn{2}{|c|}{ Kernel type } \\
\cline { 2 - 3 } & Exponential & Bi-square \\
\hline Moran's index & 0.153 & 0.112 \\
\hline Expected index & 0.000632 & 0.000632 \\
\hline Z-Score & 11.72 & 12.03 \\
\hline P-value & 0.000 & 0.000 \\
\hline
\end{tabular}

\section{CONCLUSIONS}

Due to the increase in landslide, especially in cities and the emergence of human, financial and environmental risks, the identification of criteria affecting the occurrence of landslide is of great importance. Therefore, by identifying these criteria, we can prevent this phenomenon as much as possible by using public education to the people, enacting effective management laws and policies, and more oversight in order to deal with the stimulus criteria for increasing landslide rates. Therefore, in this study, we tried to analyze the role of spatial criteria affecting in predicting landslide sensitive risk, which has been neglected in many previous studies.

The models used in previous research were not very suitable for spatial data and in most cases the spatial correlation and non-stationarity of the data were ignored. To achieve the main purpose of this study, the spatial and non-spatial data-driven models including GWR and ANN model were used to predict landslide sensitive risk based on the effective criteria. The results showed that the GWR model used, taking into account the characteristics of spatial autocorrelation and spatial nonstationarity, has higher accuracy in predicting landslide sensitive risk based on the effective criteria. In this study, an attempt was also made to determine the effective criteria in predicting landslide sensitive risk in the form of another study purpose. Therefore, the binary particle swarm optimization algorithm was used in combination with the ANN and GWR models, which showed that the criteria have a significant effect in predicting landslide sensitive risk (study area). The important point is that the mentioned method is not limited to this case study and can be used to predict the landslide sensitive risk in various types of regions.

Due to the success of the spatial data-driven model used in this research, it is suggested for future research other spatial data-driven models such as Generalized Method of Moments Estimation for Spatial Autoregressive (GMM-SAR), Matrix Exponential Spatial Specification (MESS) and combination of GWR with neural networks were used. 


\section{R E F E R E N C E S}

Aad G, Abbott B, Abdallah J, Abdel Khalek S, et al. (2014) Measurements of spin correlation in top-antitop quark events from proton-proton collisions at $\sqrt{s}_{\mathrm{s}}=7 \mathrm{TeV}$ using the ATLAS detector. Physical Review D - Particles, Fields, Gravitation and Cosmology 90: . https://doi.org/10.1103/PhysRevD.90.112016

Abed KA, Ahmad AA (2020) The best parameters selection using pso algorithm to solving for ito system by new iterative technique. Indonesian Journal of Electrical Engineering and Computer Science 18: . https://doi.org/10.11591/ijeecs.v18.i3.pp1638-1645

Aghbashlo M, Tabatabaei M, Nadian MH, Davoodnia V, Soltanian S (2019) Prognostication of lignocellulosic biomass pyrolysis behavior using ANFIS model tuned by PSO algorithm. Fuel 253: . https://doi.org/10.1016/j.fuel.2019.04.169

Amir Yazdadi E, Ghanavati E (2016) Landslide Hazard Zonation by using AHP (Analytical Hierarchy Process) model in GIS (Geographic Information System) Environment (Case study: Kordan Watershed)

Baharvand S, Rahnamarad J, Soori S, Saadatkhah N (2020) Landslide susceptibility zoning in a catchment of Zagros Mountains using fuzzy logic and GIS. Environmental Earth Sciences 79:204 . https://doi.org/10.1007/s12665-020-08957-w

Bai SB, Wang J, Lü GN, Zhou PG, Hou SS, Xu SN (2010) GIS-based logistic regression for landslide susceptibility mapping of the Zhongxian segment in the Three Gorges area, China. Geomorphology 115:23-31 . https://doi.org/10.1016/j.geomorph.2009.09.025

Ciurleo M, Cascini L, Calvello M (2017) A comparison of statistical and deterministic methods for shallow landslide susceptibility zoning in clayey soils. Engineering Geology 223:71-81 . https://doi.org/10.1016/j.enggeo.2017.04.023

El_Jerjawi NS, Abu-Naser SS (2018) Diabetes Prediction Using Artificial Neural Network. International Journal of Advanced Science and Technology 121:55-64 . https://doi.org/10.14257/ijast.2018.121.05

Elfil M, Negida A (2019) Sampling methods in clinical research; an educational review. Archives of Academic Emergency Medicine 7:52 . https://doi.org/10.22037/emergency.v5i1.15215

Felicísimo ÁM, Cuartero A, Remondo J, Quirós E (2013) Mapping landslide susceptibility with logistic regression, multiple adaptive regression splines, classification and regression trees, and maximum entropy methods: A comparative study. Landslides 10:175-189 . https://doi.org/10.1007/s10346-0120320-1

Fotheringham AS, Oshan TM (2016) Geographically weighted regression and multicollinearity: dispelling the myth. Journal of Geographical Systems 18: . https://doi.org/10.1007/s10109-016-0239-5

Ghorbanzadeh O, Pourmoradian S, Blaschke T, Feizizadeh B (2019) Mapping potential nature-based tourism areas by applying GIS-decision making systems in East Azerbaijan Province, Iran. Journal of Ecotourism 18:261-283 . https://doi.org/10.1080/14724049.2019.1597876

Guevara J, Zadrozny B, Buoro A, Lu L, Tolle J, Limbeck J, Wu M, Hohl D (2018) A hybrid data-driven and knowledge-driven methodology for estimating the effect of completion parameters on the cumulative production of horizontal wells. In: Proceedings - SPE Annual Technical Conference and Exhibition. Society of Petroleum Engineers (SPE)

Jin KP, Yao LK, Cheng QG, Xing AG (2019) Seismic landslides hazard zoning based on the modified Newmark model: a case study from the Lushan earthquake, China. Natural Hazards 99:493-509 . https://doi.org/10.1007/s11069-019-03754-6

Kennedy J, Eberhart RC (1997) Discrete binary version of the particle swarm algorithm. In: Proceedings of the IEEE International Conference on Systems, Man and Cybernetics

Lee S, Hong SM, Jung HS (2018) GIS-based groundwater potential mapping using artificial neural network and support vector machine models: the case of Boryeong city in Korea. Geocarto International 33:847861 . https://doi.org/10.1080/10106049.2017.1303091

Lo C-M, Feng Z-Y, Chang K-T (2018) Landslide hazard zoning based on numerical simulation and hazard assessment. Geomatics, Natural Hazards and Risk 9:368-388 . https://doi.org/10.1080/19475705.2018.1445662 
Murray AT, Xu J, Baik J, Burtner S, Cho S, Noi E, Pludow BA, Zhou E (2020) Overview of Contributions in Geographical Analysis: Waldo Tobler. In: Geographical Analysis

Neaupane KM, Piantanakulchai M (2006) Analytic network process model for landslide hazard zonation. Engineering Geology 85:281-294 . https://doi.org/10.1016/j.enggeo.2006.02.003

Oktorie O (2017) A Study of Landslide Areas Mitigation and Adaptation in Palupuah Subdistrict, Agam Regency, West Sumatra Province, Indonesia. Sumatra Journal of Disaster, Geography and Geography Education 1:43 . https://doi.org/10.24036/sjdgge.v1i1.34

Oshan TM, Li Z, Kang W, Wolf LJ, Stewart Fotheringham A (2019) MGWR: A python implementation of multiscale geographically weighted regression for investigating process spatial heterogeneity and scale. ISPRS International Journal of Geo-Information 8: . https://doi.org/10.3390/ijgi8060269

Paulino Â de C, Guimarães LNF, Shiguemori EH (2019) Hybrid adaptive computational intelligence-based multisensor data fusion applied to real-time UAV autonomous navigation. Inteligencia Artificial 22:162-195 . https://doi.org/10.4114/intartif.vol22iss63pp162-195

Rajabi M, Vlizadeh Kamran K, Abedi Gheshlaghi H (2016) Evaluation and zoning landslide hazard by using the analysis network process and artificial neural network (case study Azarshahr Chay basin). 5:60-74

Saeidian B, Mesgari MS, Pradhan B, Ghodousi M (2018) Optimized location-allocation of earthquake relief centers using PSO and ACO, complemented by GIS, clustering, and TOPSIS. ISPRS International Journal of Geo-Information 7: . https://doi.org/10.3390/ijgi7080292

Wang X, Liu H (2019) A Knowledge-and Data-Driven Soft Sensor Based on Deep Learning for Predicting the Deformation of an Air Preheater Rotor. IEEE Access 7:159651-159660 . https://doi.org/10.1109/ACCESS.2019.2950661

Wu D (2020) Spatially and temporally varying relationships between ecological footprint and influencing factors in China's provinces Using Geographically Weighted Regression (GWR). Journal of Cleaner Production 261: . https://doi.org/10.1016/j.jclepro.2020.121089

Xu K, Guo Q, Li Z, Xiao J, Qin Y, Chen D, Kong C (2015) Landslide susceptibility evaluation based on BPNN and GIS: a case of Guojiaba in the Three Gorges Reservoir Area. International Journal of Geographical Information Science 29:1111-1124 . https://doi.org/10.1080/13658816.2014.992436

Zemestani A, Soori H (2019) Relationship between fatal road traffic injury rates and Human Development Index in Iran. Journal of Injury and Violence Research 11:

Zhang Y, Wu W, Qin Y, Lin Z, Zhang G, Chen R, Song Y, Lang T, Zhou X, Huangfu W, Ou P, Xie L, Huang X, Peng S, Shao C (2020) Mapping Landslide Hazard Risk Using Random Forest Algorithm in Guixi, Jiangxi, China. ISPRS International Journal of Geo-Information 9:695 . https://doi.org/10.3390/ijgi9110695 